\title{
Nelfinavir targets multiple drug resistance mechanisms to increase the efficacy of doxorubicin in MCF-7/Dox breast cancer cells
}

Geetika Chakravarty $^{1}$, Aditi Mathur ${ }^{1}$, Pallavi Mallade ${ }^{1}$, Samantha Gerlach ${ }^{1}$, Joniece Willis ${ }^{1}$, Amrita Dutta $^{2}$, Sudesh Srivastava ${ }^{3}$, Asim B. Abdel-Mageed ${ }^{2}$ and Debasis Mondal ${ }^{1, *}$

Departments of Pharmacology ${ }^{1}$ and Urology ${ }^{2}$, Tulane University Medical Center. Department of Biostatistics ${ }^{3}$, Tulane University School of Public Health and Tropical Medicine, New Orleans, LA 70112. USA

Running title: Nelfinavir suppresses MDR phenotype in breast cancer cells

Key words: Breast cancer, MDR, Doxorubicin, Nelfinavir, Chemosensitization, Tumor xenograft

\section{* Corresponding Author}

Dr. Debasis Mondal, Ph.D.

Associate Professor

Department of Pharmacology, SL-83, Tulane University School of Medicine 1430 Tulane Avenue, New Orleans, LA, 70112 Phone: (504) 988-4668; Fax: (504) 588-5283.

E-mail: $\underline{\text { dmondal@tulane.edu }}$ 


\section{Abstract}

Development of multidrug resistance (MDR) remains a significant problem in cancer chemotherapy, and underscores the importance of using chemosensitizers. Well known MDR mechanisms include: (i) upregulation of drug-efflux; (ii) increased signaling via AKT; and (iii) decreased apoptosis. Therefore, chemosensitizers should target multiple resistance mechanisms. We investigated the efficacy of nelfinavir (NFV), a clinically approved anti-HIV drug, in increasing doxorubicin (DOX) toxicity in a MDR breast cancer cell line, MCF-7/Dox. As compared to parental MCF-7 cells, the MCF-7/Dox were 15-20 fold more resistant to DOXinduced cytotoxicity at $48 \mathrm{hr}$ post-exposure (DOX $\mathrm{IC}_{50}=1.8 \mu \mathrm{M} v$ s. $\left.32.4 \mu \mathrm{M}\right)$. Coexposures to NFV significantly $(\mathrm{p}<0.05)$ decreased DOX-IC 50 in MCF-7/Dox cells. Multiple exposures to physiologic concentrations of NFV $(2.25 \mu \mathrm{M}$ or $6.75 \mu \mathrm{M})$ decreased DOX-IC ${ }_{50}$ by 21 -fold and 50-fold, respectively. Interestingly, although single exposure to NFV could transiently induce Pglycoprotein (P-gp) levels, multiple treatments with NFV inhibited both P-gp expression and efflux function and increased intracellular DOX concentrations. Single exposure to NFV also augmented the markers of cell-survival (AKT) and autophagy (LC3-II), whereas multiple exposures enabled suppression of both total AKT (t-AKT) and insulin like growth factor-1 (IGF1)-induced phosphorylated AKT (p-AKT) levels. Multiple exposures to NFV also resulted in increased unfolded protein response (UPR) transducers, e.g. Grp78, p-PERK, p-eIF2 $\alpha$, and ATF4; and endoplasmic reticulum (ER) stress induced death sensors, e.g. CHOP \& TRIB-3. Multiple exposures to NFV also abrogated the mitogenic effects of IGF-1. In mice carrying MCF-7/Dox tumor xenografts, intraperitoneal (i.p.) injection of NFV (20 mg/kg/day) and DOX $(2 \mathrm{mg} / \mathrm{kg} / \mathrm{twice} / \mathrm{wk})$ decreased tumor growth more significantly $(\mathrm{p}<0.01)$ than either agent alone. Immunohistochemical (IHC) analysis revealed decreased p-AKT and Ki-67 levels. Thus, NFV overcome MDR in breast cancer cells and should be used as an adjunct to chemotherapy. 


\section{Introduction}

Breast cancer is the second leading cause of cancer-related mortality in women in the United States [1]. Patient's age, race and body mass index (BMI) are crucial determinants of cancer progression to aggressive disease [2]. Despite recent advances in the early detection of malignancy and improvements in surgery and radiation for localized tumors [3, 4] a significant number of patients manifest recurrent and metastatic disease [5]. Furthermore, even with the numerous treatments currently available against metastatic breast cancer, e.g. anti-estrogens, tyrosine kinase inhibitors (TKIs) and immunotherapeutics, evolution of resistant tumor clones poses a significant challenge $[6,7]$. A cytotoxic chemotherapy regimen, primarily consisting of anthracyclines (e.g. doxorubicin) and taxanes (e.g. paclitaxel) is the last resort in these patients $[8,9]$. Approximately $60 \%$ of all patients with breast cancer ultimately undergo chemotherapy. However, only a minority of patients on chemotherapy show long-term remission and their suboptimal response rate accounts for high rate of failure and selection of chemoresistant tumors [10-12]. Therefore, significant efforts are being made to develop agents that can suppress the MDR phenotype of breast cancer cells $[13,14]$.

One of the mechanisms by which tumor cells acquire MDR phenotype is induction of drug-efflux pumps [15-17]. The ATP-binding cassette (ABC) transporters such as Pglycoprotein (P-gp or $\mathrm{ABCB} 1 / \mathrm{MDR} 1), \mathrm{MDR}$ related proteins (MRP), lung resistance protein (LRP), and breast cancer resistance protein (BCRP) can efflux a number of chemotherapeutic agents. Indeed, augmented levels of both P-gp and BCRP have been often associated with resistance to both anthracyclines and taxanes $[18,19]$. Therefore, a strategy to circumvent drug resistance via coadministration of competitive inhibitors is being actively investigated [17]. However, in order to overcome the high constitutive expression of ABC-transporters in MDR 
tumor clones, a sustained chemosensitizing effect would need to be achieved. Furthermore alternate survival pathways responsible for the resurgence of aggressive cancers will need to be targeted. Chemosensitizers should both act as efflux-pump inhibitors (EPI) and should also downregulate these crucial survival mechanisms $[20,21]$.

Growth factors and cytokines within inflammatory tumor microenvironments can facilitate tumor growth and survival [2]. Frequent overexpression of insulin/insulin like growth factor-1 (IGF-1) receptors on breast cancer cells can lead to the stimulation of survival signaling via the activation of PI3K/AKT/mTOR pathway $[22,23]$. Indeed, tumor cells with acquired resistance display constitutive AKT activation (phosphorylation) and chemotherapeutic agents are known to activate this survival mechanism in cancer cells $[24,25]$. The PI3K/AKT/mTOR signaling pathway is also known to upregulate P-gp (MDR-1) expression and function [26, 27]. In addition to the PI3K/AKT/mTOR signaling axis, a number of other crucial survival mechanisms are also becoming important drug resistance mechanisms. Two newly discovered metabolic pathways, i.e. autophagy and unfolded protein response (UPR) are essential for cancer cell survival in stressful tumor microenvironments [28, 29]. Autophagy is a catabolic process that maintains homeostasis in response to increased metabolic demands [28]. Tumor cells activate autophagy by preventing the accumulation of damaged proteins via increased protein degradation and turnover of cell organelles. Autophagy-mediated cell survival or cell death decisions can also be exquisitely regulated by the UPR pathways [29]. In aggressive cancer cells, escape from chemotherapy-induced apoptosis is facilitated by a mild UPR, and the crosstalk between autophagy and PI3K/AKT/mTOR cascades. On the other hand, although the UPR cascade initially favors cellular homeostasis and survival, uncontrolled UPR results in the ensuing endoplasmic reticulum (ER)-stress that dictates apoptosis [30]. Indeed, pharmacological agents that target ER-stress are becoming promising anticancer agents [31, 32]. 
A number of natural compounds, e.g. curcumin, genistein and resveratrol, are being tested as relatively safe chemosensitizers. However, the preclinical successes with these phytochemicals have not translated to the clinic, primarily due to their low bioavailability in vivo $[33,34]$. Furthermore, clinical approval of new agents that are able to target multiple drug resistance mechanisms in aggressive cancer cells would be an expensive and time-consuming process. Hence, drug repositioning strategies are becoming a viable alternative and a highly rewarding approach $[35,36]$. Indeed, numerous studies have shown that the clinically approved drug nelfinavir (NFV) may inhibit AKT phosphorylation and induce ER-stress in cancer cells [35-37]. In contrast to the side effects seen with experimental MDR-modulators, NFV has been used chronically in HIV-positive patients and has relatively fewer side effects. The enthusiasm to use NFV as a chemosensitizing agent is clearly reflected by several ongoing cancer clinical trials [38]. The availability of chemosensitizers with known pharmacokinetics and toxicity profiles will be of significant benefit in the clinic [15]. However, although NFV is an inhibitor of P-gp [39] it may also induce P-gp expression since it is also a substrate [40, 41], thus compromising its anticancer efficacy.

Using the MCF-7/Dox cells, an aggressive breast cancer cell line that overexpresses P-gp and show constitutive AKT and UPR levels [42], we have shown that physiologically achievable concentrations of NFV $(<7.0 \mu \mathrm{M})$ can increase doxorubicin (DOX)-induced cytotoxicity. Molecular mechanistic studies demonstrated that coexposure to NFV can overcome multiple compensatory drug resistance mechanisms in vitro. Using in vivo MCF-7/Dox tumor xenografts, we have shown that coexposure to NFV can enhance the anti-tumor effects of DOX.

\section{Materials and Methods}


2.1. Cell culture. The human breast adenocarcinoma cell line, MCF-7 was purchased from American Type Culture Collection (ATCC; Manassas, VA, USA). The DOX resistant MCF7/Dox cells were a generous gift from Dr. Kapil Mehta (M. D. Anderson Cancer Center, Houston, TX, USA) [42]. Both cell lines were maintained in Eagle's Minimum Essential Medium (EMEM), with Earle's balanced salt solution (EBSS), containing 10\% fetal bovine serum (FBS), penicillin and streptomycin, L-glutamine, non-essential amino acids (NEAA), and sodium pyruvate (Gibco-BRL, Grand Island, NY). Cells were grown at $37^{\circ} \mathrm{C}$ in a humidified incubator with $5 \% \mathrm{CO}_{2}$. The MDR phenotype of MCF-7/Dox cells was maintained by continuous selective pressure using medium supplemented with $50 \mathrm{ng} / \mathrm{mL}$ of doxorubicin.

2.2. Reagents. Experiments were carried out using both pure nelfinavir purchased from Sigma (St. Louis, MO) and extracted from Viracept ${ }^{\mathrm{TM}}$ tablets $(250 \mathrm{mg})$ obtained from Agouron pharmaceuticals (San Diego, CA). Doxorubicin was purchased from Sigma-Aldrich (St. Louis, MO). Calcein-AM was purchased from Molecular Probes (Eugene, OR USA). Verapamil was purchased from EMD Chemicals (Gibbstown, NJ USA). Primary antibody against P-gp [Mdr1 Antibody (C-19): sc-1517] was purchased from Santa Cruz Biotechnology (Santa Cruz, CA). Antibodies against phosphor-PERK (Threonine-980), ATF-4, TRIB-3 and Goat anti-rabbit secondary antibody were purchased from Santa-Cruz Biotechnology (Santa Cruz, CA). Antibodies against total-AKT and phospho-AKT (Serine-473), total-eIF2 $\alpha$ and phospho-eIF2 $\alpha$ (Serine-51), Grp78/BiP, CHOP, and LC3, were all obtained from Cell Signaling (Danvers, MA). Antibody against $\beta$-Actin and GAPDH were purchased from Fisher Scientific (Waltham, MA) and antibody against Ki-67 was from Spring Biosciences (Pleasanton, CA).

2.3. Cell viability assays. Cell viability was measured using the MTT reagent $\{3-(4,5-$ dimethylthiazol-2-yl)-2, 5-diphenyltetrazolium bromide\} and according to our published protocols [32]. In brief, cells $\left(5 \times 10^{3}\right.$ cells/well) were plated in 96-well plates and allowed to adhere overnight. Desired concentrations of compounds, alone or in different combinations, 
were added to cells in six replicate wells and the cytotoxic effects of NFV, alone and in combination with DOX, were determined by MTT-assays. DOX $(0.1-30 \mu \mathrm{M})$ was either added at the same time as NFV $(0.75-6.75 \mu \mathrm{M})$ or was added after overnight pre-exposure to NFV. In 'single' exposure experiments, cells were coexposed to NFV and DOX for $48 \mathrm{hrs}$; and in the 'multiple' exposures experiments, cells were first treated with NFV for $16 \mathrm{hr}$ and then reexposed to both NFV and DOX for another $48 \mathrm{hr}$. Following drug treatments, MTT was added to each well and incubated for 3 hrs. Formazan crystals were detected by measuring the absorbance at $540 \mathrm{~nm}$ with a $\mu$ Quant plate reader (Bio-Tek; Seattle, WA). Percent change in cell survival compared to untreated controls was calculated.

2.4. Drug-efflux assays. Calcein-AM (a P-gp substrate) was used to measure drug-efflux function $[17,43]$. Briefly, cells $\left(1 \times 10^{4}\right)$ were plated in 24-well Krystal black plates (Labnet International; Woodbridge, NJ) and drug exposures initiated the next day. Each plate contained background wells (no cell), cells with no treatment (negative control), cells exposed to Verapamil (positive control) or with NFV and/or DOX (experimental). For acute effects of drug exposure, cells were incubated with NFV or Verapamil $(0.75-6.75 \mu \mathrm{M})$ for 15 min prior to the addition of Calcein-AM $(0.25 \mu \mathrm{M})$ and further incubation for another $15 \mathrm{~min}$ before fluorescence measurements. For prolonged effects of 'single or multiple' drug exposures, cells were treated with NFV for $16 \mathrm{hr}$, and either the drug was removed or replenished for another 30 min before the addition of Calcein-AM. Following 15 min incubation with Calcein, cells were washed 3times with cold phosphate-buffered saline (PBS) and intracellular Calcein retention was measured by using an Flx800 fluorescence microplate reader (BioTek). Excitation and emission wavelengths were set at $485 \pm 20 \mathrm{~nm}$ and $528 \pm 20 \mathrm{~nm}$, respectively. Cells were then lysed and total protein contents measured in each well. Mean fluorescence units per $\mu \mathrm{g}$ of protein $(\mathrm{MFU} / \mu \mathrm{g})$ were calculated and normalized to controls. 
2.5. Fluorescence microscopy. Intracellular DOX accumulation in the presence or absence of NFV was monitored by fluorescence microscopy [43]. The MCF7/Dox cells $\left(5 \times 10^{4}\right)$ were grown on coverslips that were submerged in media in 6-well tissue culture plates. Cells were pre-incubated for 30 minutes with NFV $(0-6.75 \mu \mathrm{M})$ prior to the addition of DOX $(3.0 \mu \mathrm{M})$ and further incubation was carried out for another $1 \mathrm{hr}$. Cells were washed with PBS, coverslips were removed and treated with Vectashield mounting medium containing DAPI (Vector Labs, Burlingame, CA USA). Intracellular DOX retention, which fluoresces red upon excitation with green light $(\lambda \mathrm{ex}=470 \pm 20 \mathrm{~nm}, \lambda \mathrm{em}=590 \pm 20 \mathrm{~nm})$, were measured using a fluorescent Nikon Eclipse E400 microscope (Melville, NY USA) attached to the EXFO X-Cite 120 fluorescence illuminator system (Mississauga, ON, CAN).

2.6. Immunoblot analysis. Immunoblot studies were carried out according to our past publication [32]. Both short-term (8-16 hr) and long-term (64 hr) effects of NFV and/or DOX were evaluated. In specified experiments to measure activated AKT (p-AKT) levels, cells were first exposed to NFV for $48 \mathrm{hr}$ and then stimulated either acutely (30 min) or long-term (16 hrs) with IGF-1 (10 ng/ml). Cells were harvested and whole cell lysates were obtained using cell lysis buffer (Cell Signaling; Danvers, MA). Proteins were quantified with BCA protein assay reagent (Thermo Scientific; Rockford, IL). Approximately $30 \mu \mathrm{g}$ of proteins were electrophoresed on $10 \%$ sodium dodecyl sulfate-polyacrylamide (SDS-PAGE) gels from BioRad (Hercules, CA). Proteins were wet transferred to a PVDF membrane (Bio-Rad) at 90V for 2 $\mathrm{hr}$ and blocked with bløk ${ }^{\mathrm{TM}}-\mathrm{CH}$ chemiluminescent blocker (Millipore) for $1 \mathrm{hr}$ at room temperature. Membranes were then probed with the desired primary (1:200 to 1:1000 dilutions) and secondary antibodies (1:1000 dilution). Bands were detected using SuperSignal West Pico chemiluminescent substrate (Thermo Scientific) and band intensities were quantified using the Image-J software (NIH). Densitometric values were normalized to corresponding $\beta$-actin or GAPDH levels and fold changes were calculated. 
2.7. Flow cytometry. Flow cytometry assays were carried out to measure cell surface P-gp levels by using a phycoerythrine (PE)-labeled P-gp antibody (C-19). Briefly, MCF7/Dox cells $\left(1 \times 10^{6}\right)$ were treated with NFV $(0.75-6.75 \mu \mathrm{M})$ for $16 \mathrm{hr}$. Next day, cells were washed with PBS, harvested with $0.05 \%$ trypsin/0.025 \% EDTA and re-suspended in wash buffer. The PElabeled P-gp antibody or its isotype (IgG) control (1:200 dilution) was added to this cell suspension and incubated at $4^{\circ} \mathrm{C}$ for $30 \mathrm{~min}$ in the dark. Cells were washed in PBS containing $0.05 \%$ Tween-20, resuspended in ice cold PBS, and analyzed on a Beckman Coulter Epics FC500 flow cytometer with CXP software (Brea, CA). Both forward and side scatter gatings were performed with unlabeled cells.

2.8. Tumor xenografts. Tumor xenograft studies were carried out according to our past publications [32, 43]. All animal protocols were approved by the Animal Care and Use Committee (IACUC) of Tulane University and were conducted in accordance with NIH guidelines. Animals were housed in sterile filtered cages and given food and water ad libitum and maintained at $21-22^{\circ} \mathrm{C}$ with a $12 \mathrm{hr} / 12 \mathrm{hr}$ light and dark cycle. Briefly, female athymic nude BALB/c mice (6-8 week old) were obtained from Charles River Laboratories (Wilmington, MA USA) and were allowed to acclimate for one week prior to experimentations. Prior to injection, the MCF7/Dox cells $\left(5 \times 10^{6}\right)$ were resuspended in equal volume of serum free medium (SFM) containing Matrigel, and $100 \mu$ of the suspension was injected orthotopically into the fourth inguinal mammary gland of each mouse. Tumors were allowed to grow to 50 $\mathrm{mm}^{3}$ ( $\sim 2$ weeks) at which time the intraperitoneal (i.p.) injection of drugs were initiated. Tumor bearing mice were randomly divided into 4 treatment groups ( $\mathrm{n}=6 \mathrm{mice} / \mathrm{grp})$, (i) vehicle control; (ii) NFV (20 mg/kg daily); (iii) DOX (2 mg/kg every 3 days), or (iv) NFV (20 mg/kg daily) and DOX ( $2 \mathrm{mg} / \mathrm{kg}$ every 3 days) combination. Both drugs were diluted in vehicle (4\% DMSO, 5\% polyethylene glycol, 5\% Tween 80 in saline) immediately before administration. At the end of 
treatment (6 weeks) tumor sizes were measured using a Vernier caliper and tumor volumes were calculated using the formula: length $\times$ width $^{2} \times 0.4$. Mice were then sacrificed and tumors harvested and sectioned for immunohistochemical (IHC) analysis.

2.9. Immunohistochemistry. The IHC staining of tumor sections were carried to measure the proliferation marker Ki-67 and the survival marker p-AKT [32]. Briefly, resected tumors were fixed in $10 \%$ neutral buffered formalin followed by incubation in $70 \%$ ethanol and embedding in paraffin. Paraffin blocks were sectioned using a microtome $(\sim 5 \mu \mathrm{m})$ and stained with hematoxylin and eosin (H\&E). Slides were deparaffinized, hydrated, and antigen retrieval carried out using $10 \mathrm{mM}$ citrate buffer $\left(\mathrm{pH}\right.$ 6.0) and then incubated with $3 \% \mathrm{H}_{2} \mathrm{O}_{2}$ and $1.5 \%$ blocking serum (Vector laboratories; Burlingame, CA). Slides were then incubated with antibodies against Ki-67 or p-AKT for 60 min at room temperature, washed twice in PBS and incubated with biotinylated secondary antibody. Slides were treated with the Vectastain enzyme reagent (Vector laboratories) and then stained with diaminobenzidine (DAB) and counterstained using Hematoxylin nuclear stain (Vector laboratories). Staining was visualized and captured using an Eclipse E-400 microscope (Nikon Instruments, Melville, NY). Five different fields from each slide were used to analyze and quantify p-AKT and Ki-67 positive cells by Image-J software.

2.10. Statistical analysis. Data was summarized using descriptive statistics such as mean, standard deviation, proportions and standard errors. Mann-Whitney U tests were used to compare between control, NFV or DOX alone, and with NFV+DOX combination groups. Oneway ANOVA was performed to compare the differences in tumor volume in mice treated with NFV, DOX, and NFV+DOX. All statistical analyses were performed at the 5\% level of significance $(\mathrm{p}<0.05)$ using the GraphPad Prism software (La Jolla, CA). 


\section{Results}

3.1. Coexposure to NFV potentiates DOX-induced cytotoxicity. We compared DOX (0.1$100 \mu \mathrm{M}$ ) induced cytotoxicity in both MCF-7 and MCF-7/Dox cells and fifty percent inhibitory concentration $\left(\mathrm{IC}_{50}\right)$ was determined. The DOX- $\mathrm{IC}_{50}$ values at $64 \mathrm{hr}$ post-exposure were $1.8 \mu \mathrm{M}$ in MCF-7 cells and 32.4 $\mu \mathrm{M}$ in MCF-7/Dox cells (Fig.1A). This confirmed the resistant phenotype of MCF-7/Dox cells. We also measured the concentration dependent cytotoxicity of NFV $(0.75-22.5 \mu \mathrm{M})$ following either single $(48 \mathrm{hr})$ or multiple $(16 \mathrm{hr}+48 \mathrm{hr})$ exposures (Fig.1B). The physiologic concentrations of NFV $(0.75-6.75 \mu \mathrm{M})$ showed less than $20 \%$ cell killing; however, the supra-physiologic concentration of NFV $(22.5 \mu \mathrm{M})$ showed $60-70 \%$ toxicity. Therefore, all of our experiments were carried out using the physiologically achievable concentrations of NFV $(<7 \mu \mathrm{M})$ and using DOX concentrations lower than its $\mathrm{IC}_{50}(<3 \mu \mathrm{M})$.

To investigate the chemosensitizing ability of NFV, we measured the effect of 'single' or 'multiple' exposures on DOX-induced cytotoxicity. For 'single' exposure studies cells were coexposed to both DOX and NFV for $48 \mathrm{hr}$, and for 'multiple' exposure studies cells were first pre-exposed to NFV for $16 \mathrm{hr}$ and then re-exposed to both NFV \& DOX for another $48 \mathrm{hr}$. Both single (Fig.1C) and multiple (Fig.1D) exposures to NFV were able to significantly $(\mathrm{p}<0.01)$ decrease DOX-IC 50 in the MCF-7/Dox cells. Single exposure to the low $(2.25 \mu \mathrm{M})$ or high dose $(6.75 \mu \mathrm{M})$ of NFV decreased $\mathrm{DOX}-\mathrm{IC}_{50}$ from $32.4 \mu \mathrm{M}$ to $13.5 \mu \mathrm{M}$ and $5.2 \mu \mathrm{M}$, respectively. However, multiple treatments with both low and high dose NFV further decreased DOX-IC 50 to $6.4 \mu \mathrm{M} \& 1.85 \mu \mathrm{M}$, respectively. Indeed, a precipitous drop in cell viability was clearly evident even with the lower concentrations of DOX when cells were coexposed to NFV. This demonstrated the ability of NFV to chemosensitize MCF-7/Dox cells. Furthermore, cells exposed multiple times to NFV showed significantly higher killing ability. Therefore, 
mechanistic studies were carried out to monitor the temporal effects of NFV in suppressing different drug resistance mechanisms in the MCF-7/Dox cells.

\subsection{Acute effects of NFV on drug-efflux function and intracellular DOX levels. We} quantified drug efflux function in MCF-7/Dox cells by using the fluorescent dye Calcein-AM and the known P-gp inhibitor, verapamil, [43]. Several of the HIV protease inhibitors, including NFV, are known to be competitive inhibitors of P-gp [39,44]. Therefore, we first tested whether NFV can suppress drug-efflux and increase DOX retention in these MDR cells (Fig. 2). Cells were pre-incubated with either verapamil or $\operatorname{NFV}(0.75-6.75 \mu \mathrm{M})$ for $30 \mathrm{~min}$ before the addition of Calcein-AM or DOX. Intracellular fluorescence was measured after another 15 min for Calcein incubation (Fig. 2A) or after $2 \mathrm{hr}$ for DOX incubation (Fig. 2B). As shown in Fig. 2A, equimolar concentrations of verapamil or NFV pre-incubation could suppress Calcein efflux and clearly established NFV as a potent inhibitor of drug-efflux function. As shown in Fig. 2B, fluorescence microscopy images similarly showed increased DOX retention in MCF7/Dox cells following coexposure to increasing concentrations of NFV (Fig. 2B). Cells exposed to DOX (3 $\mu \mathrm{M}$ ) alone had very little intracellular DOX accumulation even after $2 \mathrm{hr}$ incubation (Fig. 2B, top). However, a profound increase in intracellular DOX-fluorescence (red) was observed in cells that were pre-exposed to NFV (Fig. 2B, bottom panels). Therefore, acute exposure to NFV shows a potent inhibitory effect on P-gp mediated drug efflux to increase DOX levels in cells.

\subsection{Differential effects of low vs. high dose NFV on P-gp expression and drug-efflux}

function. Although acute exposure to NFV may decrease P-gp function via competitive inhibition, by being a substrate, prolonged exposure to NFV may also result in increased P-gp levels, and thus augment MDR function instead [39]. Therefore, we monitored the effects of both acute and long-term exposures to NFV on Calcein efflux and P-gp expression (Fig.3). We compared the effects of either acute $(30 \mathrm{~min})$ or prolonged treatments with NFV, in either single 
(16 hr) or multiple $(16 \mathrm{hr}+30 \mathrm{~min})$ exposure studies. Experiments on intracellular Calcein retention showed drastically different dose- and time-dependent effects of NFV on drug-efflux function. Similar to our previous study (Fig.2), acute exposure to NFV (30 min) decreased drugefflux function (Fig. 3A). However, single pre-exposure to low-dose of NFV (2.25 $\mu \mathrm{M})$ for as short as $16 \mathrm{hr}$ was shown to increase drug-efflux function, as evident by lower Calcein retention (Fig. 3A). This increased drug-efflux function was potent so that it could not be fully suppressed by competitive inhibition with acute $(30 \mathrm{~min})$ coexposure to NFV. On the other hand, in both 'single' and 'multiple' exposure studies, high dose of NFV $(6.75 \mu \mathrm{M})$ showed significant $(p<0.01)$ suppression in efflux function $(15$-fold $)$. More importantly, this sustained suppressive effect on P-gp function was further enhanced following acute exposure to NFV, as evident almost 30-fold increase in Calcein retention. This clearly showed the advantage of multiple exposures to high dose NFV as a superior approach for suppression of drug-efflux mechanisms in MDR cancer cells.

In order to understand this differential dose- and time-dependent effect of NFV on drugefflux function, we monitored P-gp protein levels in NFV exposed MCF7/Dox cells (Fig.3). Immunoblot studies were carried out to measure total P-gp protein expression (Fig.3, B \& C) and cell surface P-gp levels were quantified by flow cytometry (Fig. 3D). We documented increases in both a lower molecular-weight P-gp band (unglycosylated) and a higher molecular-weight Pgp band (glycosylated) in these immunoblots (Fig. 3B). Exposure to low-dose NFV (2.25 $\mu \mathrm{M})$ showed a temporal increase in P-gp protein (140 - $170 \mathrm{kDa})$ levels, which was evident as early as $4 \mathrm{hr}$ post-treatment (1.3-fold) and was significantly higher at $16 \mathrm{hr}$ post-exposure. Prolonged NFV exposure showed a 2.5 fold increase in the lower P-gp band and a 5.2-fold increase in the higher P-gp band (Fig. 3B, lane-4). Data from Figure-3B clearly indicated that low dose NFV $(2.25 \mu \mathrm{M})$ may increase both total and glycosylated P-gp levels. Since the dose- and time- 
dependent effects of exposure to NFV had differential effects on drug-efflux function, we measured the effects of high dose NFV $(6.75 \mu \mathrm{M})$ on P-gp protein levels (Fig.3C). Although prolonged exposure to the lower concentrations of NFV $(0.75 \mu \mathrm{M} \& 2.25 \mu \mathrm{M})$ increased both total and glycosylated P-gp (Fig. 3C, lane-3) the high dose of NFV (6.75 $\mu \mathrm{M})$ was able to overcome this induction and decreased both the upper and lower P-gp bands (Fig. 3C, lane-4).

Glycosylated P-gp translocate to the cell surface and function as drug-efflux transporters [43]. We monitored whether NFV has a dose-dependent effect on cell surface expression of P-gp (Fig. 3D). Flow cytometry studies revealed that prolonged exposure to the lower doses of NFV $(0.75 \& 2.25 \mu \mathrm{M})$ increased cell surface P-gp levels. However, exposure to the higher dose of NFV (6.75 $\mu \mathrm{M})$ suppressed cell surface P-gp expression. Although MCF7/Dox cells constitutively expresses P-gp, in the absence of substrate (DOX stimuilation) majority of cells showed low cell surface levels. We observed that, under control conditions approximately 7.96 $\%$ of the cell population expressed high cell surface P-gp. However, within $16 \mathrm{hr}$ post-exposure to the lower concentrations of NFV $(0.75 \& 2.25 \mu \mathrm{M})$ was effective in increasing P-gp in 20$30 \%$ of these cells. Interestingly, this P-gp overexpressing subpopulation was substantially reduced in cells treated with the high dose of NFV $(6.75 \mu \mathrm{M})$ and only $1.53 \%$ of the cell population showed higher P-gp levels (C2 quadrant). Furthermore, even the constitutive P-gp expression was lower in rest of the cell population (C4 quadrant). This indicated that MCF7/Dox cells may activate P-gp function as a survival mechanism to evade the actions of low dose NFV; however, high concentrations of NFV may overcome this survival mechanism and suppress P-gp expression. This indicated that multiple exposures to high doses of NFV would be the optimal chemosensitization approach to increase DOX toxicity against MDR cancer cells.

3.4. Subverting UPR towards ER-stress as a chemosensitization approach. To facilitate their therapeutic resistance, cancer cells can upregulate the unfolded protein response (UPR) 
which then increase several survival mechanisms, e.g. autophagy and PI3K/AKT [29-32]. In the UPR pathway, the ER resident chaperone glucose related protein-78 (Grp78) is bound to several transducers, i.e. PKR-like ER kinase (PERK), inositol requiring enzyme 1 (IRE1), and activating transcription factor-6 (ATF-6). Following stress, the release, activation, and subsequent nuclear localization of these UPR transducers can ultimately dictate homeostasis or progression to apoptosis. Since previous studies have shown that NFV may inhibit AKT phosphorylation and induce both autophagy and ER-stress [35-37] we focused our attention on PERK activation and ER-stress [45, 46]. In this pathway (Fig.4A), activated (phosphorylated) PERK in-turn phosphorylates and inactivates the eukaryotic translational initiation factor $2 \alpha$ (eIF2 $\alpha$ ) which represses global protein synthesis to enable recovery from stress. However, this is also coincident with preferential translation of several master regulators of ER-stress such as activating transcription factor-4 (ATF-4) and C/EBP homologous protein (CHOP). Continued synthesis of ATF-4 occurs due to low translation initiation rates and ribosomal by-pass of several false start codons upstream of the true ATF-4 start codon [47]. In response to continuous stress, increased ATF-4 and CHOP leads to upregulation of the ER-stress death sensor, tribbles homolog-3 (TRIB-3). Studies by us [32] and others [48, 49] have shown that the switch between survival and apoptosis is critically regulated by the levels of ATF-4, CHOP and TRIB-3. The pseudokinase function of TRIB-3 can downregulate the function of several crucial transcription factors [50] and initiates cell death by activating mitochondrial caspases [51].

\subsection{NFV rapidly subverts UPR towards ER-stress in DOX exposed MCF-7/Dox cells.}

We measured the effects of NFV and DOX on the above ER-stress transducers. We first investigated whether short-term exposure $(8 \mathrm{hr})$ to NFV and DOX can increase the markers of UPR (Fig.4B). Although NFV, alone or in combination with DOX, did not increase the early UPR transducers Grp78 (Fig.4B) or PERK (not shown), several downstream transducers were upregulated. Enhanced levels of p-eIF2 $\alpha$ were observed with increasing NFV concentrations, 
which were further increased (2.8-fold) following coexposure to NFV and DOX. Similarly, although ATF-4 expression did not increase with NFV or DOX alone, its expression was enhanced (1.8-fold) following coexposure to NFV and DOX. Under basal (unstimulated) conditions, the MCF-7/Dox cells expressed low levels of CHOP. However, a 1.5-fold increase in CHOP expression was observed with NFV and, most importantly, CHOP levels were significantly increased (3.6-fold) following coexposure to NFV and DOX. Thus, coexposure to NFV and DOX can rapidly increase the expression of ER-stress death sensors.

\subsection{Resurgent survival pathways in DOX exposed cells are blocked by NFV coexposure.}

Increased PI3K/AKT signaling is linked to DOX resistance in breast cancer cells [21, 52]. Autophagy is another survival mechanism utilized by cancer cells to escape chemotherapy [28, 53]. Both of these pathways also interact with UPR to facilitate cellular homeostasis, and suppress ER-stress induction and apoptosis in cancer cells [54]. Therefore, we investigated the effects of NFV $(0.75-6.75 \mu \mathrm{M})$ on both AKT-activation (Fig.4C) and autophagy-induction (Fig.4D). MCF-7/Dox cells showed constitutive levels of total-AKT (t-AKT) and significant AKT activation (p-AKT) was documented within 15 min post-exposure to IGF-1 (10 ng/ml). However, exposure to even low doses of NFV $(0.75 \& 2.25 \mu \mathrm{M})$ resulted in a $50 \%$ decrease in pAKT levels. Interestingly however, short-term exposure to even the highest dose of NFV (6.75 $\mu \mathrm{M})$ also caused a reactivation of p-AKT levels.

The microtubule-associated ubiquitin-like light chain protein, LC3 is often used to monitor autophagy $[36,48]$. The processing of pro-LC3 to LC3-I, and subsequently to the autophagosome bound LC3-II demonstrates autophagy induction. Therefore, we monitored LC3-I and LC3-II levels in cells exposed to DOX, alone and in combination with NFV (Fig. 4D). Immunoblot analysis showed that exposure to NFV $(6.75 \mu \mathrm{M})$ significantly increased LC3-I levels by 2.3 -fold, and cotreatment with NFV and DOX increased both LC3-I (7.2-fold) and 
LC3-II (5.2-fold) levels. Thus, multiple survival pathways are resurgent in these MDR cancer cells following exposure to chemotherapy and their activation can be blocked by NFV.

3.7. NFV overcomes the protective effects of IGF-1 on DOX-induced cytotoxicity. We investigated whether prolonged exposure to physiologic concentrations of NFV can suppress the resurgence of growth factor induced survival signaling in MCF-7/Dox cells (Fig.5). Cells were coexposed to DOX $(3.0 \mu \mathrm{M})$ and NFV $(0-6.75 \mu \mathrm{M})$ for $48 \mathrm{hr}$ and then exposed to IGF-1 for 16 hr for immunoblot analysis and MTT assays. Immunoblots for p-AKT, t-AKT, Grp78, p-PERK, CHOP and TRIB-3 levels are shown in both control (untreated) and drug exposed cells (Fig.5A). As compared to untreated cells, IGF-1 stimulated cells showed a 4.5 -fold increase in p-AKT levels. However, long-term coexposure to NFV showed a dose-dependent suppression in IGF-1 induced p-AKT levels. Interestingly, prolonged exposure to the high dose NFV $(6.75 \mu \mathrm{M})$ could also drastically reduce total AKT (t-AKT) levels. Although long-term (48 hr) exposure to DOX alone was able to increase basal levels of ER-stress markers (e.g. CHOP, Grp78 and p-PERK) coexposure to NFV further increased both Grp78 and p-PERK levels by 3.4-fold and 2.5-fold, respectively. In addition, both CHOP and TRIB-3 levels were also increased by 3.7 -fold and 5.2-fold, respectively. These profound increases in ER-stress death sensors were clearly evident in the DOX and NFV coexposed cells especially after their stimulation with IGF-1. This clearly indicated that chronic NFV exposure can subvert the cell survival pathways towards ER-stress induced cell death. This potent chemosensitizing effect was also corroborated in MTT cell survival assays (Fig.5B). We observed that exposure to IGF-1 (10 ng/ml) can significantly increase cell proliferation and decreased DOX $(1-10 \mu \mathrm{M})$ induced cell death. However, coexposure to NFV $(2.75 \& 6.75 \mu \mathrm{M})$ sensitized these IGF-1 stimulated cells to even the low doses of DOX $(<3 \mu \mathrm{M})$. In IGF-1 treated cells, combined exposure to DOX and NFV showed profound increase in cell death $(70-90 \%)$. Thus, chronic exposure to NFV can overcome the 
protective effects of growth factors within tumor microenvironments. In fact, cells stimulated with IGF-1 were found to be more susceptible to DOX-induced cytotoxicity when chronically exposed to NFV, in vitro.

\subsection{NFV potentiates the anti-tumor efficacy DOX in mouse tumor xenografts in vivo.}

Previous studies by us [32] and others [55, 56] have documented the anti-tumor effects of chronic NFV treatment in different tumor xenograft models. Here, we tested whether chronic treatment with NFV and DOX combination can reduce MCF-7/Dox tumor growth in vivo (Fig.6). To demonstrate the DOX sensitizing effects of NFV, we used the NFV (20 $\mathrm{mg} / \mathrm{kg} / 5 \mathrm{x} /$ week) and DOX (2 $\mathrm{mg} / \mathrm{kg} / 2 \mathrm{x} /$ week) doses that were previously shown to have minimal deleterious effect on the overall well-being of mice $[56,57]$. Orthotopic tumors $(50$ $\mathrm{mm}^{3}$ ) were first developed in immunocompromised mice. Animals were then randomized into four treatment groups for intraperitoneal (i.p.) injections of the following drugs for 6 wks: (i) vehicle, (ii) NFV, (iii) DOX or (iv) NFV+DOX. Comparison of tumor volumes $\left(\mathrm{mm}^{3}\right)$ showed that chronic exposure to DOX or NFV alone can reduce tumor growth by $43 \%$ and $30 \%$, respectively. However, mice treated with combination of these two drugs showed a reduction to as much as $65-80 \%$ (Fig. 6A). Statistical analyses indicated that the NFV and DOX co-treated tumors were significantly $(\mathrm{p}=0.013)$ smaller than the untreated control mice. Tumors were harvested and expression of p-AKT and Ki-67 were monitored (Fig. 6B \& 6C). The IHC analysis of tumor sections clearly showed decreased expression of both p-AKT (Fig.5B) and Ki67 (Fig.5C). Quantitative analysis of Ki-67 stained cells showed that $70-80 \%$ of cells in untreated tumors were positive for the cell proliferation marker, Ki-67. However, mice exposed to the drug combination showed significant suppression in Ki-67 staining (Fig. 6D). Therefore, our in vivo studies corroborated our in vitro findings and clearly indicated that NFV can potentiate the antitumor efficacy of DOX. 


\section{Discussion}

Acquired drug resistance occurs as a response to drug exposure and changes in the tumor microenvironments, and is a significant challenge in targeting breast cancer. The development of chemoresistance is also a persistent problem due to the inherent MDR phenotype of cancer stem cells (CSC) [59]. Although DOX is one of the most effective chemotherapeutic agents against aggressive breast cancers, its efficacy is significantly compromised due to the inherent and/or acquired drug-efflux and survival mechanisms $[7,8]$. Our investigations suggested that multiple signaling pathways are augmented in the MCF-7/Dox cells and enable them to overcome the initial cytotoxic effects of chemotherapy. However, our findings also demonstrated that these survival mechanisms can be overcome by chronic coexposures to clinically achievable concentrations of NFV.

The increased demands on the ER to ensure tumor cell viability and survival, clearly implicates that pharmacological interference of ER function would be an attractive approach for anticancer therapy. The proof of principle of this concept of exploiting the pre-existing ER-stress in tumors to initiate apoptosis has been provided by both our in vitro and in vivo studies, and suggests that clinical studies to validate this concept in cancer patients would be essential. Since NFV is orally available and FDA approved, its clinical evaluation as an anticancer agent could be expedited and our findings address the critical need for its expedited development as an effective chemosensitizing agent.

A number of previous studies, by us [32] and others [36-38], have suggested that NFV should be repositioned as an anticancer agent. Although, the anticancer effects of NFV is consistent with a number of previous reports [36,38], earlier studies did not evaluate the effect of NFV on drug resistant cancer cells. In addition, it is not known whether its anticancer effects involve suppression of drug-efflux mechanisms or whether its potency may be hampered due to 
an induction in MDR phenotype. Our current findings, using the P-gp overexpressing MCF7/Dox cells, suggested that the multipronged actions of chronic high doses of NFV can be very effective against MDR breast cancer cells. Mechanistically, this is significant because growth factor receptor activation can be a common means for AKT activation and could be clinically relevant because IGF-IR are targets for cancer therapy.

In vitro investigations showed that NFV can simultaneously suppress P-gp mediated drug efflux, inhibit growth factor induced AKT activation, and subvert the UPR pathway towards ERstress. Although studies using competitive inhibitors of P-gp function have not shown significant promise, adjuvant therapies with signal transduction inhibitors that suppress P-gp expression are emerging as novel approaches to delay the onset of multidrug resistance [60]. However, the paradoxical observations that, in contrast to high-dose NFV the low-dose NFV can increase P-gp expression and function, bring out hitherto unreported characteristics of this P-gp substrate. Indeed, this observation needs to be properly reconciled before the regular use of NFV as adjuvants with anti-cancer agents. The profound P-gp suppression observed with the higher concentration $(6.75 \mu \mathrm{M})$ of NFV may be directly linked to its potent anticancer effects in in vivo tumor xenografts. Since the dosing regimen for our xenograft studies was daily and since NFV has rapid clearance (half-life of 3 to $5 \mathrm{~h}$ in humans) it is possible that the efficacy of NFV may be further improved by the addition of other drugs that decrease its metabolism.

Although initial increases in drug-efflux function may be due to the substrate induced effects on P-gp localization to the membrane, the decrease in P-gp expression seen with chronic NFV exposure may be associated with the inhibition of AKT signaling [24, 60]. Activation of the PI3K/AKT signaling pathway has been linked to therapeutic resistance, and both NFV and DOX may acutely increase AKT levels in tumor cells. However, we believe that NFV's ability to simultaneously suppress AKT activation and augment ER-stress can overcome the initial inductive effects on P-gp. Furthermore, this potent inhibition of p-AKT levels may also switch 
the balance of cell survival and cell death in the aggressive cancer cells. In DOX and NFV coexposed cells, we have documented significant increases in ER-stress death sensors, e.g. CHOP and TRIB-3. These proteins target both kinase activation and mitochondrial caspases, and override the protective effects of growth factor induced p-AKT [23, 24] and drug-induced autophagy $[28,53]$.

The two main mechanisms linked to the anti-cancer activity NFV seem consistently to be both ER-stress induction and AKT inhibition [61]. Although most studies have focused on the effects of NFV on tumor cells only, it is possible that NFV may possess other anti-tumor mechanisms [62]. Angiogenesis plays a crucial role in in vivo tumor growth and ER-stress is known to suppress endothelial cell function and angiogenesis. Therefore, down regulation of tumor associated vasculature may contribute to the potent anti-tumor effects of NFV. Significant suppression of in vivo tumor growth with NFV and DOX combination may suggest its effect on the tumor vasculature as well, which clearly corroborates the benefits of using chronic NFV therapy as a chemosensitizer against MDR cancer cells.

Therapeutic efficacy of NFV may be further increased by using compounds that contribute to ER stress aggravation via alternate molecular mechanisms. This approach will enable the use of lower concentrations of each individual agent and reduce drug-related toxicities. The convergence of ER stress and other cell survival systems may also result in a more profound antitumor synergy. Indeed, we had previously demonstrated that the NF- $\kappa \mathrm{B}$ inhibitor curcumin can synergize with NFV to increase its anticancer effects in castrationresistant prostate cancer (CRPC) cells [32]. In another recent study in CRPC cells, investigators showed that NFV can increase cell death by inhibiting site-2 protease (S2P) cleavage activity, which led to the suppression of regulated intramembrane proteolysis (RIP) [63]. Interestingly, RIP is necessary for post-translational processing of another UPR transducer ATF-6. Therefore, although acting via a different arm of the UPR, these findings again implicated a direct role for 
ER-stress in NFV-induced anticancer effects. Studies have also shown that NFV can inhibit the growth of HER2-positive breast cancer cells by suppressing the chaperone function of heat shock protein 90 (HSP90) and may thus increase the efficacy of numerous others Hsp90 inhibitors which are being tested as anticancer agents [63]. Ultimately, our investigations clearly show that the multipronged effects of NFV may be very beneficial in its use as an adjunct to existing chemotherapy against MDR breast cancers.

\section{Acknowledgements}

These studies were supported by funds from the Louisiana Cancer Research Consortium (LCRC) and the Department of Defense (DoD, \#PC0810811) to D.M. 


\section{References}

1: $\quad$ Altekruse SF, Krapcho M, Neyman N, Aminou R, Waldron W, Ruhl J, Howlader N, Tatalovich Z, Cho H, Mariotto A, Eisner MP, Lewis DR, Cronin K, Chen HS, Feuer EJ, Stinchcomb DG, Edwards BK (eds): SEER Cancer Statistics Review 1975-2007. Bethesda, MD: National Cancer Institute; 2010.

2: $\quad$ Santa-Maria CA, Yan J, Xie XJ, Euhus DM. Aggressive estrogen-receptor-positive breast cancer arising in patients with elevated body mass index. Int J Clin Oncol. 2015 Apr;20(2):317-23.

3: Kümmel S, Holtschmidt J, Loibl S. Surgical treatment of primary breast cancer in the neoadjuvant setting. Br J Surg. 2014 Jul;101(8):912-24.

4: Calvo FA, Sole CV, Rivera S, Meiriño R, Lizarraga S, Infante MA, Boldo E, Ferrer C, Marsiglia H, Deutsch E. The use of radiotherapy for early breast cancer in woman at different ages. Clin Transl Oncol. 2014 Aug;16(8):680-5.

5: $\quad$ Schneble EJ, Graham LJ, Shupe MP, Flynt FL, Banks KP, Nissan A, Henry L, Stojadinovic A, Shumway NM, Avital I, Peoples GE, Setlik RF. Current approaches and challenges in early detection of breast cancer recurrence. J Cancer. 2014 Mar $16 ; 5(4): 281-90$.

6: Jankowitz RC, Davidson NE. Adjuvant endocrine therapy for breast cancer: how long is long enough? Oncology (Williston Park). 2013 Dec;27(12):1210-6, 1224.

7: $\quad$ M Braden A, V Stankowski R, M Engel J, A Onitilo A. Breast cancer biomarkers: risk assessment, diagnosis, prognosis, prediction of treatment efficacy and toxicity, and recurrence. Curr Pharm Des. 2014;20(30):4879-98. 
8: $\quad$ Bines J, Earl H, Buzaid AC, Saad ED. Anthracyclines and taxanes in the neo/adjuvant treatment of breast cancer: does the sequence matter? Ann Oncol. 2014 Jun;25(6):107985.

9: Crozier JA, Swaika A, Moreno-Aspitia A. Adjuvant chemotherapy in breast cancer: To use or not to use, the anthracyclines. World J Clin Oncol. 2014 Aug 10;5(3):529-38.

10: Videira M, Reis RL, Brito MA. Deconstructing breast cancer cell biology and the mechanisms of multidrug resistance. Biochim Biophys Acta. 2014 Dec;1846(2):312-25.

11: Nandy SB, Gangwani L, Nahleh Z, Subramani R, Arumugam A, de la Rosa JM, Lakshmanaswamy R. Recurrence and metastasis of breast cancer is influenced by ovarian hormone's effect on breast cancer stem cells. Future Oncol. 2015 Mar;11(6):983-95.

12: Choi $\mathrm{YH}, \mathrm{Yu}$ AM. ABC transporters in multidrug resistance and pharmacokinetics, and strategies for drug development. Curr Pharm Des. 2014;20(5):793-807.

13: Saraswathy M, Gong S. Different strategies to overcome multidrug resistance in cancer. Biotechnol Adv. 2013 Dec;31(8):1397-407.

14: Landis-Piwowar KR, Milacic V, Chen D, Yang H, Zhao Y, Chan TH, Yan B, Dou QP. The proteasome as a potential target for novel anticancer drugs and chemosensitizers. Drug Resist Updat. 2006 Dec;9(6):263-73.

15: Brózik A, Hegedüs C, Erdei Z, Hegedus T, Özvegy-Laczka C, Szakács G, Sarkadi B. Tyrosine kinase inhibitors as modulators of ATP binding cassette multidrug transporters: substrates, chemosensitizers or inducers of acquired multidrug resistance? Expert Opin Drug Metab Toxicol. 2011 May;7(5):623-42.

16: Gottesman MM, Fojo T, Bates SE. Multidrug resistance in cancer: role of ATPdependent transporters. Nat Rev Cancer. 2002 Jan;2(1):48-58. 
17: Roy U, Chakravarty G, Honer Zu Bentrup K, Mondal D. Montelukast is a potent and durable inhibitor of multidrug resistance protein 2-mediated efflux of taxol and saquinavir. Biol Pharm Bull. 2009 Dec;32(12):2002-9.

18: Mechetner E, Kyshtoobayeva A, Zonis S, Kim H, Stroup R, Garcia R, Parker RJ, Fruehauf JP. Levels of multidrug resistance (MDR1) P-glycoprotein expression by human breast cancer correlate with in vitro resistance to taxol and doxorubicin. Clin Cancer Res. 1998 Feb;4(2):389-98.

19: Kovalev AA, Tsvetaeva DA, Grudinskaja TV. Role of ABC-cassette transporters (MDR1, MRP1, BCRP) in the development of primary and acquired multiple drug resistance in patients with early and metastatic breast cancer. Exp Oncol. 2013 Dec;35(4):287-90.

20: Provenzano A, Kurian S, Abraham J. Overcoming endocrine resistance in breast cancer: role of the PI3K and the mTOR pathways. Expert Rev Anticancer Ther. 2013 Feb;13(2):143-7.

21: McCubrey JA, Abrams SL, Fitzgerald TL, Cocco L, Martelli AM, Montalto G, Cervello M, Scalisi A, Candido S, Libra M, Steelman LS. Roles of signaling pathways in drug resistance, cancer initiating cells and cancer progression and metastasis. Adv Biol Regul. 2015 Jan;57:75-101.

22: Beckwith H, Yee D. Insulin-like growth factors, insulin, and growth hormone signaling in breast cancer: implications for targeted therapy. Endocr Pract. 2014 Nov;20(11):121421.

23: Lauring J, Park BH, Wolff AC. The phosphoinositide-3-kinase-Akt-mTOR pathway as a therapeutic target in breast cancer. J Natl Compr Canc Netw. 2013 Jun 1;11(6):670-8. 
24: Wallin JJ, Guan J, Prior WW, Edgar KA, Kassees R, Sampath D, Belvin M, Friedman LS. Nuclear phospho-Akt increase predicts synergy of PI3K inhibition and doxorubicin in breast and ovarian cancer. Sci Transl Med. 2010 Sep 8;2(48):48ra66.

25: $\quad$ Brown KK, Toker A. The phosphoinositide 3-kinase pathway and therapy resistance in cancer. F1000Prime Rep. 2015 Feb 3;7:13. doi: 10.12703/P7-13.

26: Misra S, Ghatak S, Toole BP. Regulation of MDR1 expression and drug resistance by a positive feedback loop involving hyaluronan, phosphoinositide 3-kinase, and ErbB2. J Biol Chem. 2005 May 27;280(21):20310-5.

27: Sui H, Fan ZZ, Li Q. Signal transduction pathways and transcriptional mechanisms of ABCB1/Pgp-mediated multiple drug resistance in human cancer cells. J Int Med Res. 2012;40(2):426-35.

28: Bristol ML, Emery SM, Maycotte P, Thorburn A, Chakradeo S, Gewirtz DA. Autophagy inhibition for chemosensitization and radiosensitization in cancer: do the preclinical data support this therapeutic strategy? J Pharmacol Exp Ther.2013 Mar;344(3):544-52.

29: Maurel M, McGrath EP, Mnich K, Healy S, Chevet E, Samali A. Controlling the unfolded protein response-mediated life and death decisions in cancer. Semin Cancer Biol. 2015 Mar 23. pii: S1044-579X(15)00018-8.

30: Yadav RK, Chae SW, Kim HR, Chae HJ. Endoplasmic reticulum stress and cancer. J Cancer Prev. 2014 Jun;19(2):75-88. doi: 10.15430/JCP.2014.19.2.75.

31: Nagelkerke A, Bussink J, Sweep FC, Span PN. The unfolded protein response as a target for cancer therapy. Biochim Biophys Acta. 2014 Dec;1846(2):277-84.

32: Mathur A, Abd Elmageed ZY, Liu X, Kostochka ML, Zhang H, Abdel-Mageed AB, Mondal D. Subverting ER-stress towards apoptosis by nelfinavir and curcumin coexposure augments docetaxel efficacy in castration resistant prostate cancer cells. PLoS One. 2014 Aug 14;9(8):e103109. 
33: Smoliga JM, Blanchard O. Enhancing the delivery of resveratrol in humans: if low bioavailability is the problem, what is the solution? Molecules. 2014 Oct

24;19(11):17154-72. 34: Ashburn TT, Thor KB. Drug repositioning: identifying and developing new uses for existing drugs. Nat Rev Drug Discov. 2004 Aug;3(8):673-83.

35: Roundtable on Translating Genomic-Based Research for Health, Board on Health Sciences Policy, Institute of Medicine. Drug Repurposing and Repositioning: Workshop Summary. Washington (DC): National Academies Press (US); 2014 Aug 08.

36: Gills JJ, Lopiccolo J, Tsurutani J, Shoemaker RH, Best CJ, Abu-Asab MS, Borojerdi J, Warfel NA, Gardner ER, Danish M, Hollander MC, Kawabata S, Tsokos M, Figg WD, Steeg PS, Dennis PA. Nelfinavir, A lead HIV protease inhibitor, is a broad-spectrum, anticancer agent that induces endoplasmic reticulum stress, autophagy, and apoptosis in vitro and in vivo. Clin Cancer Res. 2007 Sep 1;13(17):5183-94.

37: Shim JS, Liu JO. Recent advances in drug repositioning for the discovery of new anticancer drugs. Int J Biol Sci. 2014 Jun 10;10(7):654-63.

38: Blumenthal GM, Gills JJ, Ballas MS, Bernstein WB, Komiya T, Dechowdhury R, Morrow B, Root H, Chun G, Helsabeck C, Steinberg SM, LoPiccolo J, Kawabata S, Gardner ER, Figg WD, Dennis PA. A phase I trial of the HIV protease inhibitor nelfinavir in adults with solid tumors. Oncotarget. 2014 Sep 30;5(18):8161-72.

39: Storch $\mathrm{CH}$, Theile D, Lindenmaier H, Haefeli WE, Weiss J. Comparison of the inhibitory activity of anti-HIV drugs on P-glycoprotein. Biochem Pharmacol. 2007 May $15 ; 73(10): 1573-81$.

40: Cisternino S, Mercier C, Bourasset F, Roux F, Scherrmann JM. Expression, upregulation, and transport activity of the multidrug-resistance protein Abcg2 at the mouse blood-brain barrier. Cancer Res. 2004 May 1;64(9):3296-301. 
41: Zastre JA, Chan GN, Ronaldson PT, Ramaswamy M, Couraud PO, Romero IA, Weksler B, Bendayan M, Bendayan R. Up-regulation of P-glycoprotein by HIV protease inhibitors in a human brain microvessel endothelial cell line. J Neurosci Res. 2009 Mar;87(4):1023-36.

42: Devarajan E, Chen J, Multani AS, Pathak S, Sahin AA, Mehta K. Human breast cancer MCF-7 cell line contains inherently drug-resistant subclones with distinct genotypic and phenotypic features. Int J Oncol. 2002 May;20(5):913-20.

43: Datta A, Bhasin N, Kim H, Ranjan M, Rider B, Abd Elmageed ZY, Mondal D, Agrawal KC, Abdel-Mageed AB. Selective targeting of FAK-Pyk2 axis by alpha-naphthoflavone abrogates doxorubicin resistance in breast cancer cells. Cancer Lett. 2015 Mar 18. pii: S0304-3835(15)00189-5.

44: Roy U, Bulot C, Honer zu Bentrup K, Mondal D. Specific increase in MDR1 mediated drug-efflux in human brain endothelial cells following co-exposure to HIV-1 and saquinavir. PLoS One. 2013 Oct 3;8(10):e75374. doi:10.1371/journal.pone.0075374.

45: Verfaillie T, Rubio N, Garg AD, Bultynck G, Rizzuto R, Decuypere JP, Piette J, Linehan C, Gupta S, Samali A, Agostinis P. PERK is required at the ER-mitochondrial contact sites to convey apoptosis after ROS-based ER stress. Cell Death Differ. 2012 Nov;19(11):1880-91.

46: Cojocari D, Vellanki RN, Sit B, Uehling D, Koritzinsky M, Wouters BG. New small molecule inhibitors of UPR activation demonstrate that PERK, but not IRE1 $\alpha$ signaling is essential for promoting adaptation and survival to hypoxia. Radiother Oncol. 2013 Sep;108(3):541-7.

47: $\quad$ Brüning A, Rahmeh M, Friese K. Nelfinavir and bortezomib inhibit mTOR activity via ATF4-mediated sestrin-2 regulation. Mol Oncol. 2013 Dec;7(6):1012-8. 
48: $\quad$ Salazar M, Carracedo A, Salanueva IJ, Hernández-Tiedra S, Egia A, Lorente M, Vázquez P, Torres S, Iovanna JL, Guzmán M, Boya P, Velasco G. TRB3 links ER stress to autophagy in cannabinoid anti-tumoral action. Autophagy. 2009 Oct;5(7):1048-9.

49: $\quad$ Corcoran CA, Luo X, He Q, Jiang C, Huang Y, Sheikh MS. Genotoxic and endoplasmic reticulum stresses differentially regulate TRB3 expression. Cancer Biol Ther. 2005 Oct;4(10):1063-7.

50: Zareen N, Biswas SC, Greene LA. A feed-forward loop involving Trib3, Akt and FoxO mediates death of NGF-deprived neurons. Cell Death Differ. 2013 Dec;20(12):1719-30.

51: Qian B, Wang H, Men X, Zhang W, Cai H, Xu S, Xu Y, Ye L, Wollheim CB, Lou J. TRIB3 is implicated in glucotoxicity- and endoplasmic reticulum-stress-induced beta-cell apoptosis. J Endocrinol. 2008 Dec;199(3):407-16.

52: $\quad$ McCubrey JA, Steelman LS, Chappell WH, Abrams SL, Wong EW, Chang F, Lehmann B, Terrian DM, Milella M, Tafuri A, Stivala F, Libra M, Basecke J, Evangelisti C, Martelli AM, Franklin RA. Roles of the Raf/MEK/ERK pathway in cell growth, malignant transformation and drug resistance. Biochim Biophys Acta. 2007 Aug;1773(8):1263-84.

53: Sun WL, Chen J, Wang YP, Zheng H. Autophagy protects breast cancer cells from epirubicin-induced apoptosis and facilitates epirubicin-resistance development. Autophagy. 2011 Sep;7(9):1035-44.

54: Appenzeller-Herzog C, Hall MN. Bidirectional crosstalk between endoplasmic reticulum stress and mTOR signaling. Trends Cell Biol. 2012 May;22(5):274-82.

55: Braga-Neto MB, Oliveira BM, Rodrigues RS, Noronha FJ, Leitao RF, Brito GA, Lima AA, Guerrant RL, Warren CA. Protective effects of alanyl-glutamine supplementation against nelfinavir-induced epithelial impairment in IEC-6 cells and in mouse intestinal mucosa. Cancer Biol Ther. 2012 Dec;13(14):1482-90. 
56: Kawabata S, Gills JJ, Mercado-Matos JR, Lopiccolo J, Wilson W 3rd, Hollander MC, Dennis PA. Synergistic effects of nelfinavir and bortezomib on proteotoxic death of NSCLC and multiple myeloma cells. Cell Death Dis. 2012 Jul 19;3:e353.

57: Ottewell PD, Mönkkönen H, Jones M, Lefley DV, Coleman RE, Holen I. Antitumor effects of doxorubicin followed by zoledronic acid in a mouse model of breast cancer. $\mathrm{J}$ Natl Cancer Inst. 2008 Aug 20;100(16):1167-78.

58: Chen JS, Konopleva M, Andreeff M, Multani AS, Pathak S, Mehta K. Drug-resistant breast carcinoma (MCF-7) cells are paradoxically sensitive to apoptosis. J Cell Physiol. 2004 Aug;200(2):223-34.

59: Britton KM, Kirby JA, Lennard TW, Meeson AP. Cancer stem cells and side population cells in breast cancer and metastasis. Cancers (Basel). 2011 Apr;3(2):2106-30.

60: Lin X, Zhang X, Wang Q, Li J, Zhang P, Zhao M, Li X. Perifosine downregulates MDR1 gene expression and reverses multidrug-resistant phenotype by inhibiting $\mathrm{PI3K} / \mathrm{Akt} / \mathrm{NF}-\kappa \mathrm{B}$ signaling pathway in a human breast cancer cell line. Neoplasma. 2012;59(3):248-56.

61: Koltai T. Nelfinavir and other protease inhibitors in cancer: mechanisms involved in anticancer activity. Version 2. F1000Res. 2015. doi: 10.12688/f1000research.5827.2.

62: Guan M, Su L, Yuan YC, Li H, Chow WA. Nelfinavir and nelfinavir analogs block site-2 protease cleavage to inhibit castration-resistant prostate cancer. Sci Rep. 2015 Apr 16;5:9698. doi: 10.1038/srep09698.

63: Shim JS, Rao R, Beebe K, Neckers L, Han I, Nahta R, Liu JO. Selective inhibition of HER2-positive breast cancer cells by the HIV protease inhibitor nelfinavir. J Natl Cancer Inst. 2012 Oct 17;104(20):1576-90 


\section{Figure legends}

Figure-1. Temporal and dose-dependent effects of DOX and/or NFV on MCF-7/Dox cell viability. (A) Differential cytotoxicity to increasing DOX concentrations is shown in MCF-7 and MCF-7/Dox cells. Percent changes in cell survival, as compared to untreated controls, are shown. Significant differences in DOX-induced cytotoxicities between MCF-7 and MCF-7/Dox cells are shown as P-values. (B) Cytotoxic effects of either single (48 hr) or multiple (16 hr +48 hr) exposures to increasing concentrations of NFV are shown in MCF-7/Dox cells. Effects of either (C) single or (D) multiple exposure to NFV on DOX-induced cytotoxicity in MCF-7/Dox cells. Experiments were carried out in six replicate wells and repeated three independent times $(\mathrm{n}=3)$. Error bars represent \pm SEM and significant differences are shown as $*, \mathrm{p}<0.05$ and $* *$, $\mathrm{p}<0.01)$. Inhibitory concentration-50 $\left(\mathrm{IC}_{50}\right)$ values for $\mathrm{DOX}$ alone and following coexposure to NFV $(2.25 \mu \mathrm{M}$ or $6.75 \mu \mathrm{M})$ are provided in the lower panels.

Figure-2: Effect of acute NFV exposure on P-gp efflux function and intracellular DOX retention in MCF-7/Dox cells. (A) NFV is a potent inhibitor of drug-efflux function. MCF7/Dox cells were pre-incubated (30 min) with equimolar concentrations of NFV or Verapamil (0

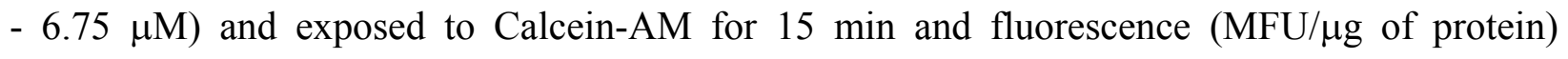
measured. Increased Calcein retention in MCF-7/Dox cells following verapamil treatment suggested P-gp function. Calcein retention in cells exposed to increasing concentrations of NFV demonstrated its potent inhibitory effect on P-gp mediated drug-efflux function. Experiments were carried out in three replicate wells and were repeated three independent times $(n=3)$. Error bars represent \pm SEM and significant differences from untreated controls are shown as; ***, $\mathrm{p}<0.001 ; * *, \mathrm{p}<0.01$ and $*, \mathrm{p}<0.05)$. (B) NFV increases intracellular DOX levels in MCF7/Dox cells. Cells were pre-treated (30 min) with NFV and then incubated with DOX $(5 \mu \mathrm{M})$ for 
60 min. Fluorescent microscopy images show intracellular DOX levels in cells exposed to increasing concentrations of NFV $(0-6.75 \mu \mathrm{M})$. Each row in the composite shows staining with DAPI alone (nuclear stain), DOX alone (red fluorescence) and the merged image. Coexposure to NFV increased intracellular DOX levels.

\section{Figure-3: Concentration and time-dependent effects of NFV on P-gp expression and efflux}

function. (A) Temporal effects of NFV on Calcein retention. Changes in drug-efflux function in MCF-7/Dox cells exposed to NFV $(2.25 \mu \mathrm{M}$ or $6.75 \mu \mathrm{M})$ during either acute exposure (30 min), following prolonged single exposure (16 hr) or following multiple exposures $(16 \mathrm{hr}+30$ min) are shown. Error bars represent \pm SEM and significant differences from untreated controls are shown as ${ }^{* *}, \mathrm{p}<0.01$ and $*, \mathrm{p}<0.05$. Significant differences between the two doses of NFV used are also shown above the bars $(\#, \mathrm{p}<0.05)$. Data clearly show that multiple treatments with high dose NFV is needed to fully suppress P-gp mediated Calcein efflux. (B) P-gp protein levels in MCF-7/Dox cells exposed to NFV $(2.25 \mu \mathrm{M})$ for $30 \mathrm{~min}, 4 \mathrm{hr}, 8 \mathrm{hr}$, and $16 \mathrm{hr}$. A representative image of the immunoblots $(\mathrm{n}=3)$ is shown. Normalized fold changes in nonglycosylated (band-1) and glycosylated (band-2) P-gp proteins are shown at the bottom. Multiple treatments with high dose NFV was able to suppress P-gp protein expression. (C) Concentration dependent effects of NFV on P-gp protein levels in MCF-7/Dox cells exposed for $16 \mathrm{hr}$. Normalized fold change in non-glycosylated and glycosylated P-gp (band-1 and band-2) are shown. (D) Flow cytometry analysis of MCF-7/Dox cells expressing cell-surface P-gp under both control conditions (untreated) and following $16 \mathrm{hr}$ exposure to increasing concentrations of NFV $(0-6.75 \mu \mathrm{M})$. Cells labeled with IgG2b (isotype control) were used to gate the P-gp negative/low cell population. Percentages of high P-gp expressing cells for NFV exposures are shown in the $\mathrm{C} 2$ quadrant. 
Figure-4: Acute effects of NFV \& DOX combination on cell survival and cell stress markers. (A) A schematic of the cross-talk between the UPR, AKT and autophagy survival pathways, and the ER-stress death sensors and progression to apoptosis. (B) Immunoblot analysis of early UPR transducers (Grp78 \& eIF-1 $\alpha$ ) and the ER-stress death sensors (ATF-4 \& CHOP) following short-term $(8 \mathrm{hr})$ exposure to $\mathrm{NFV}(0-6.75 \mu \mathrm{M})$, alone and in combination with DOX $(3 \mu \mathrm{M})(\mathrm{n}=3)$. (C) Immunoblot analysis of total AKT (t-AKT) and IGF-1 induced phosphorylated AKT (p-AKT) in cells exposed to NFV, alone and in combination with DOX $(n=3)$. (D) Immunoblot analysis of autophagy marker LC3 (LC3-1 \& LC3-II) in cells exposed to $\mathrm{NFV}$, alone and in combination with $\operatorname{DOX}(\mathrm{n}=2)$. A representative gel picture is shown for each western immunoblot experiment. Densitometric values for each band were normalized to their respective $\beta$-actin levels and fold changes are shown below each panel.

\section{Figure-5: Long-term effects of NFV \& DOX combination on cell survival and cell death} markers, and on DOX-induced cytotoxicity. MCF-7/Dox cells were exposed to DOX (3.0 $\mu \mathrm{M})$ alone or in combination with NFV $(0-6.75 \mu \mathrm{M})$ for 48 hrs. In specified samples, cells were exposed to IGF-1 (10 ng/ml) for the last $16 \mathrm{hr}$. (A) Immunoblots of p-AKT (Serine-473), tAKT, Grp78, p-PERK (Threonine-980), CHOP and TRIB-3, are shown. Densitometric values for each band were normalized to their respective controls (lane-1). (B) Cell viability assays were carried out post-exposure to DOX, NFV and/or IGF-1. Percent changes in cell survival as compared to untreated controls, are shown. Experiments were carried out in six replicate wells and error bars represent $\pm \operatorname{SEM}(n=2)$. 
Figure-6: Effect of chronic DOX and NFV treatment on MCF-7/Dox tumor xenografts in

mice. Chemosensitizing effects of drug combination on tumor growth and changes in p-AKT and Ki-67 expression. The MCF-7/Dox cells $\left(5 \times 10^{6}\right)$ were injected subcutaneously (s.c.) into the fourth inguinal mammary gland of nude mice and allowed to grow until approximately 50 $\mathrm{mm}^{3}$. Intraperitoneal (i.p.) injection was initiated with NFV $(20 \mathrm{mg} / \mathrm{kg})$ administered once daily and/or DOX (2 mg/kg) injection twice a week. Treatment was continued for six weeks before euthanization and tumor harvest. (A) Graph represents average tumor volume with each treatment modality ( $\mathrm{n}=6$ per group). Representative images of mice bearing tumors are shown in the insets. Error bars represent \pm SEM. Significant differences between DOX-only and the drug combination group are shown as, $*, \mathrm{p}<0.05$ and $* *, \mathrm{p}<0.01$. Mice were sacrificed and tumors were harvested to monitor the expression of p-AKT (B) and Ki-67 (C) by immunohistochemistry. Brown coloration (DAB) indicates p-AKT and Ki-67 staining and counterstain with Hematoxylin (blue) indicates the nuclei. (D) Quantitative analysis of Ki-67 stained cells in tumor sections (five independent fields) from control (vehicle) and drug treated groups. Percent Ki-67 positive cells are shown in the bar graphs. Error bars represent $\pm \mathrm{SEM}$. 

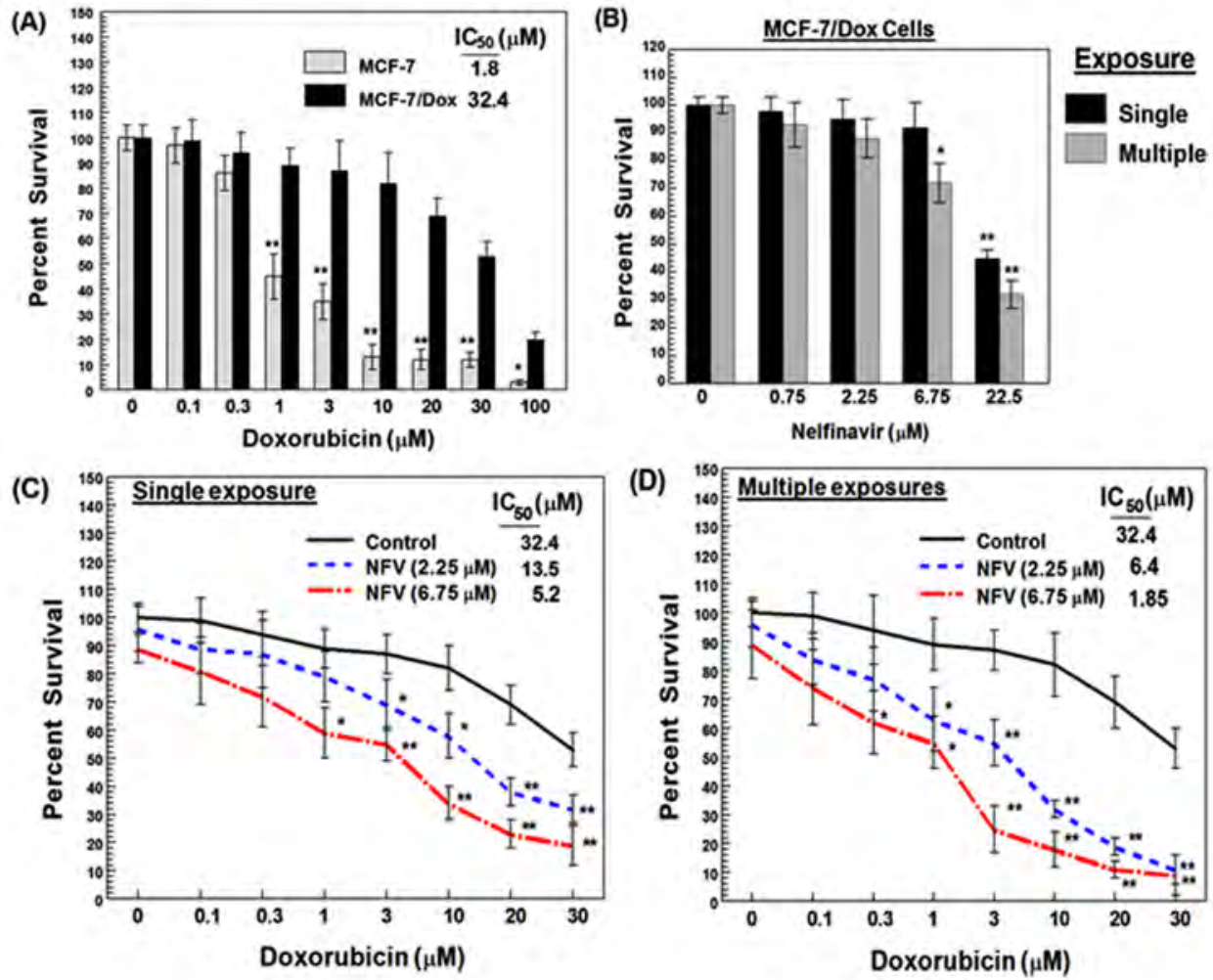

Figure-1 
(A)

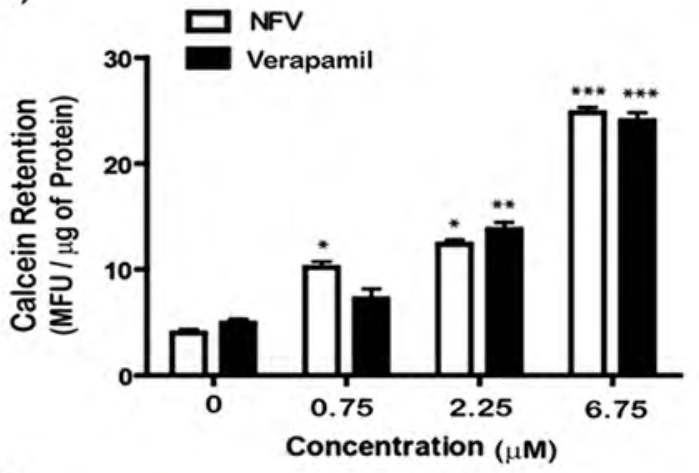

(B)

Control

DOX Uptake

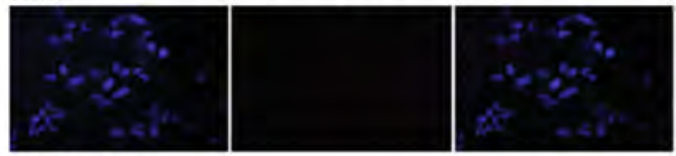

$+\mathrm{NFV}(0.75 \mu \mathrm{M})$

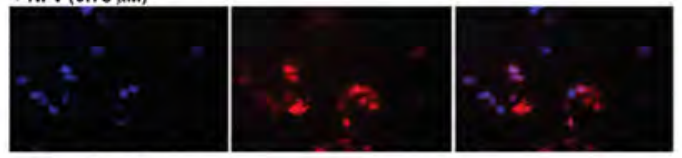

+ NFV $(2.25 \mu \mathrm{M})$

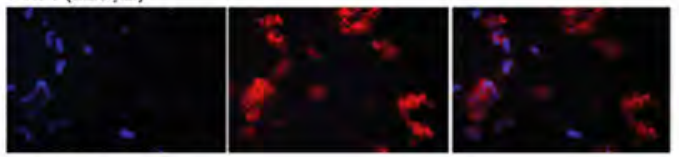

$+\operatorname{NFV}(6.75 \mu \mathrm{M})$

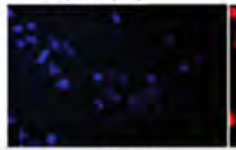

Dapi

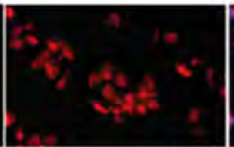

Doxorubicin

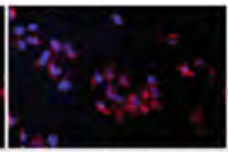

Merge

Figure-2 
(A)

\section{MCF-7/Dox}

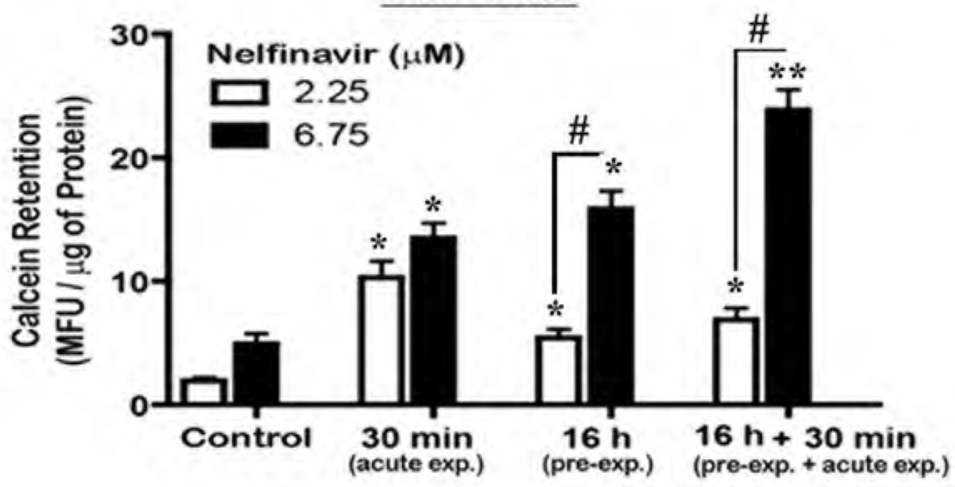

(B)

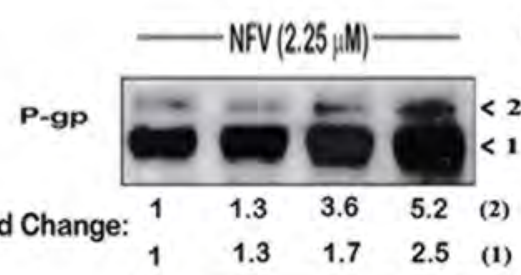

(C)

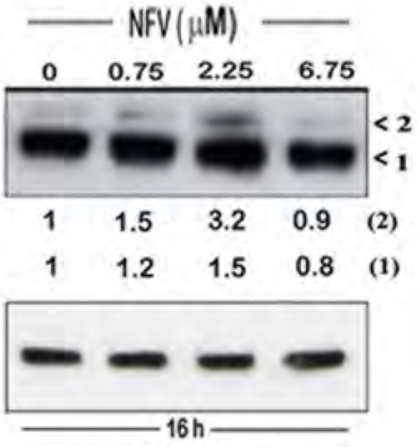

Time

(D)
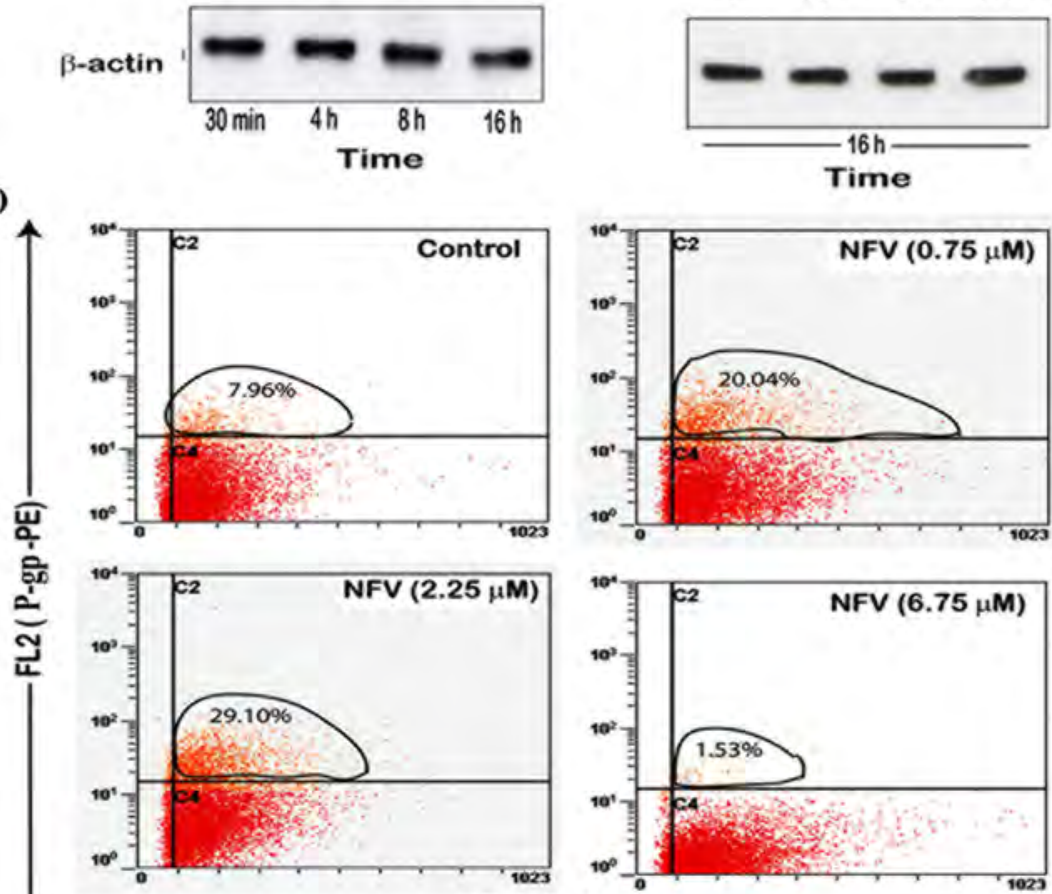

FL1 (lin)

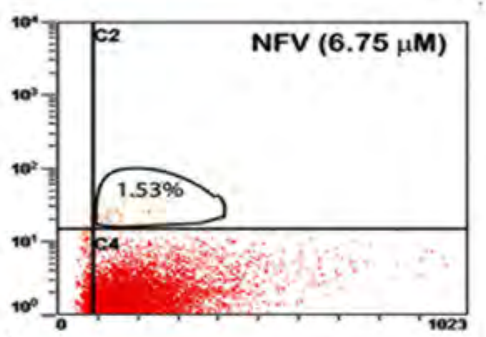


(A)

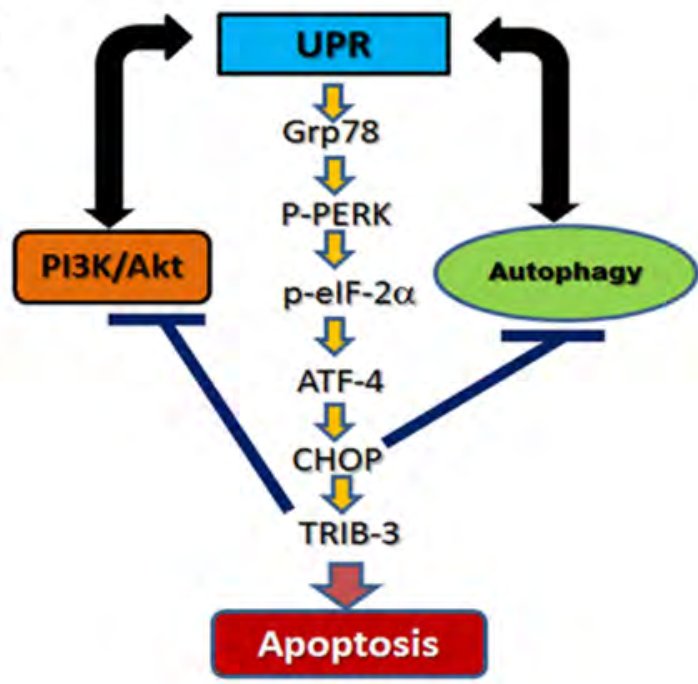

(C)

$$
\text { - IGF-1 }(10 \mathrm{ng} / \mathrm{ml})
$$

$\operatorname{Dox}(5.0 \mu \mathrm{M}): \cdot \cdot+++$

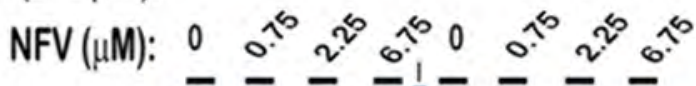

p-AKT

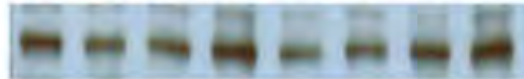

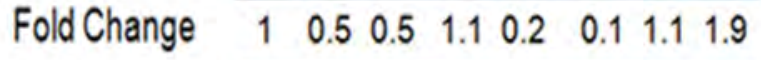

t-AKT

(D) $\operatorname{Dox}(5.0 \mu \mathrm{M}): \cdots+++$

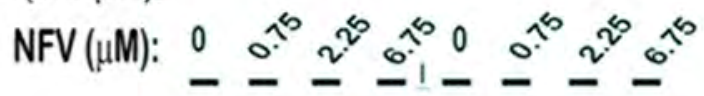

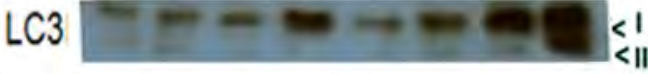

Fold Change: \begin{tabular}{llll|lllll}
1.0 & 1.1 & 0.9 & 2.3 & 1.1 & 1.6 & 2.9 & 7.2 & (I)
\end{tabular}

\begin{tabular}{llll|lllll}
1.0 & 1.1 & 0.9 & 0.9 & 0.8 & 1.2 & 1.4 & 5.2 & (II)
\end{tabular}
$\operatorname{Dox}(5.0 \mu \mathrm{M}): \cdots \cdot++++$

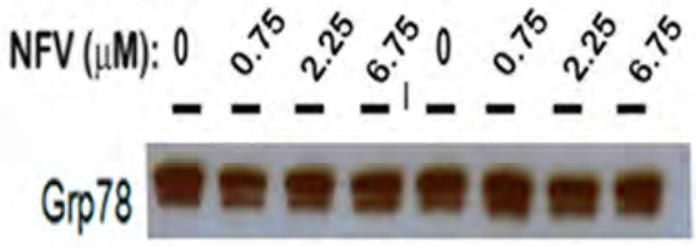

Fold Change $111.11 .41 .21 .91 .3 \quad 0.90 .8$

peelf2a $=-\cdots---\infty$

Fold Change $1 \quad 1.5 \quad 0.81 .2 \quad 1 \quad 1.31 .22 .8$

telf $2 a-\infty-\infty-0-0$

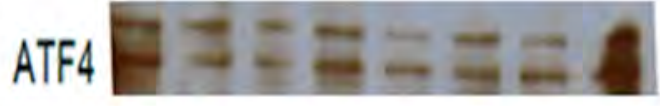

Fold Change $1 \quad 0.80 .7 \quad 1.1 \quad 0.7 \quad 0.7 \quad 0.51 .8$

CHOP

Fold Change $1 \quad 1.20 .91 .5 \quad 0.71 .32 .53 .6$

$\beta$-Actin

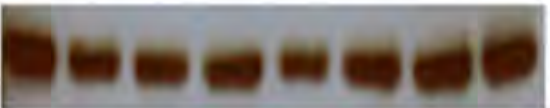

Figure-4 
(A)

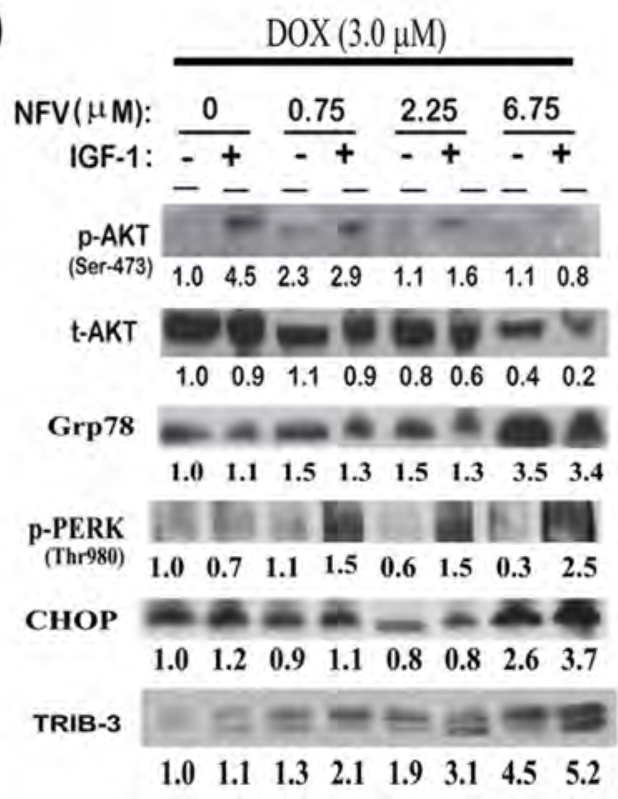

(B)

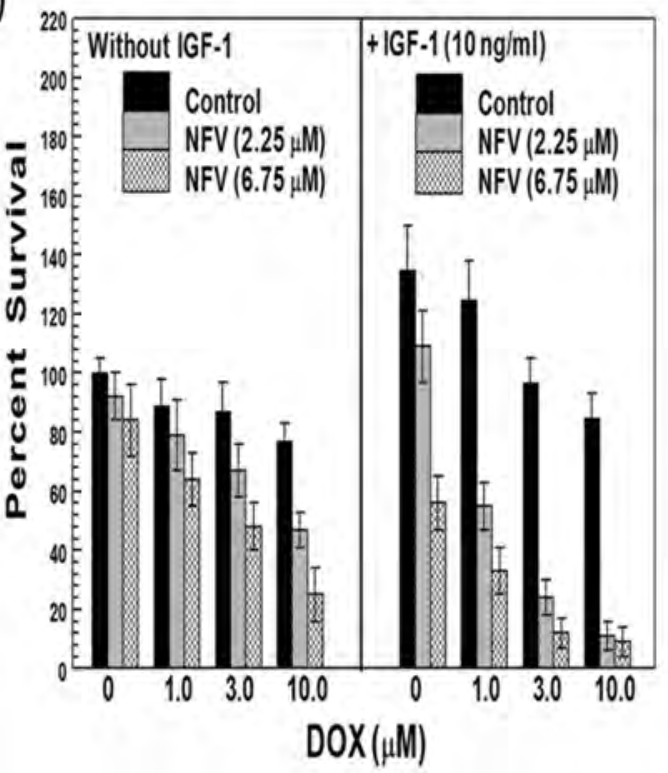

Figure-5 
(A)

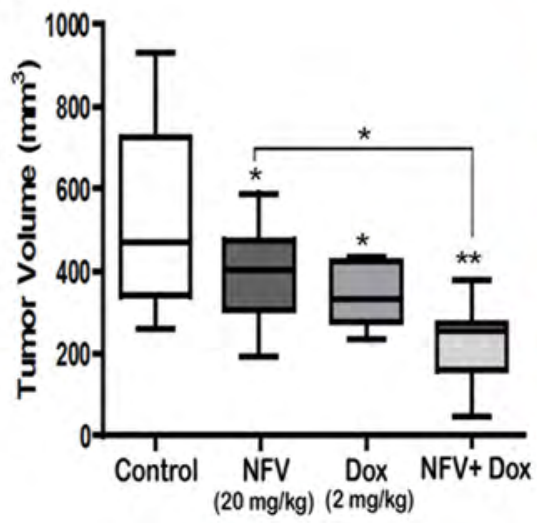

(C)

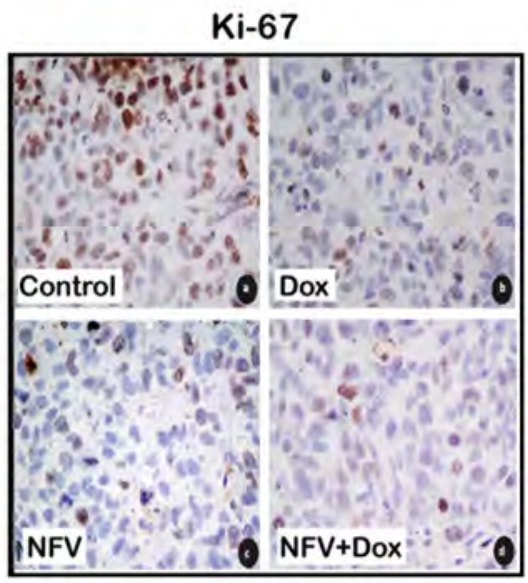

(B)
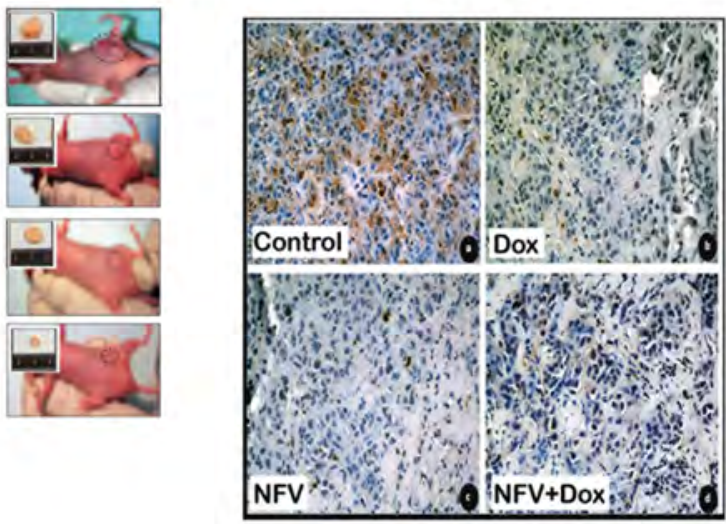

(D)

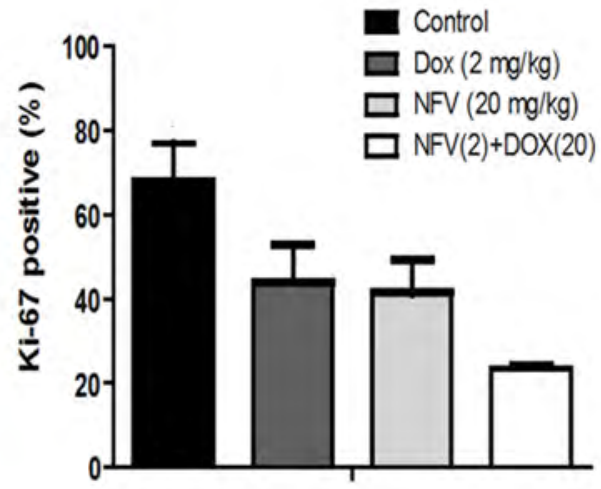

Figure-6 


\section{Multimodal Actions of Nelfinavir in Cancer Chemosensitization}

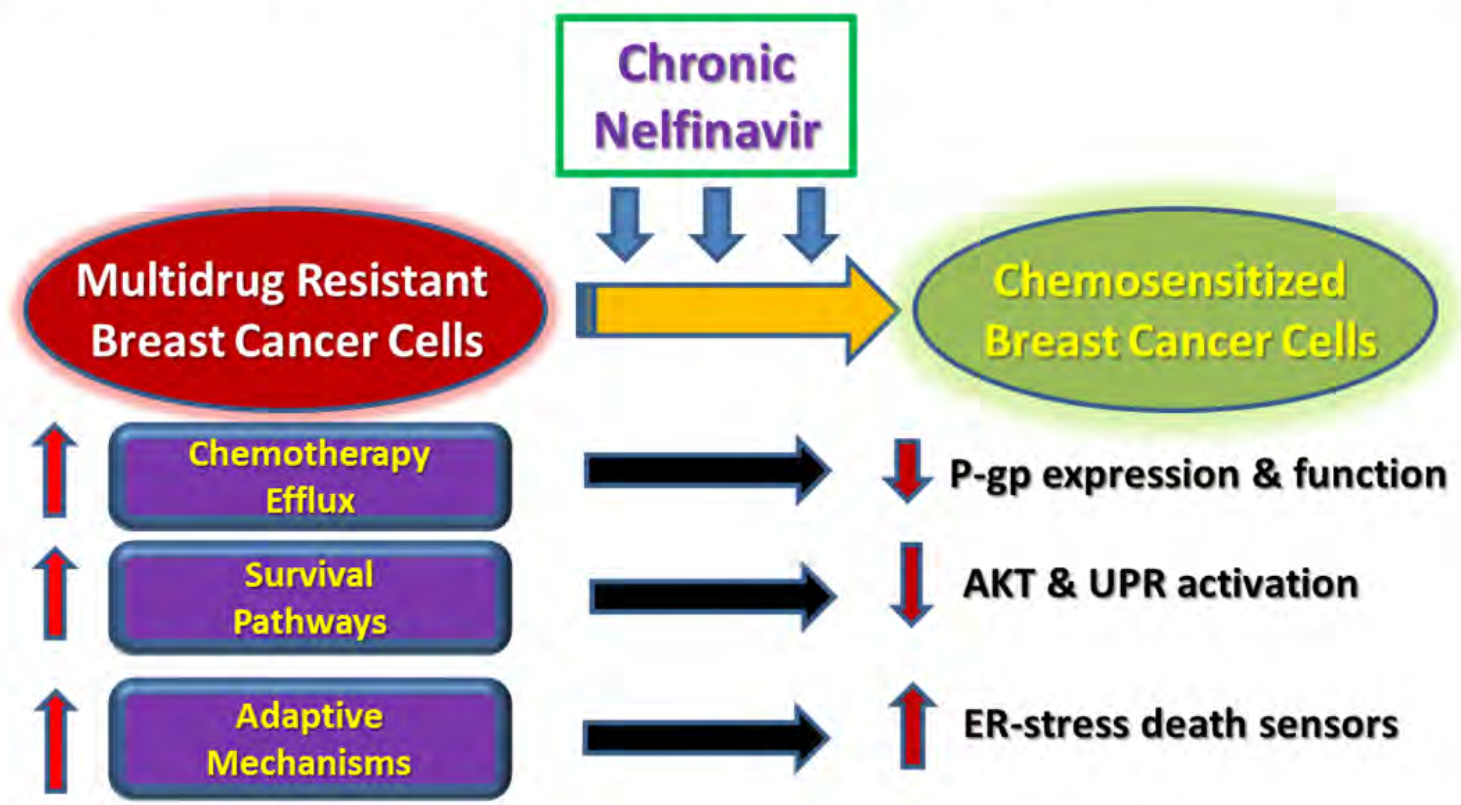

